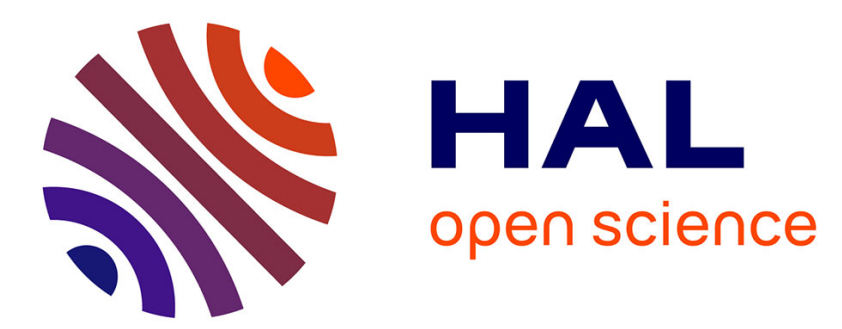

\title{
ANALYSIS AND CRITIQUE OF THE "PEAKING EFFECT" MODELS : II
}

C. Esnouf, Gilbert Fantozzi

\section{To cite this version:}

C. Esnouf, Gilbert Fantozzi. ANALYSIS AND CRITIQUE OF THE "PEAKING EFFECT" MODELS : II. Journal de Physique Colloques, 1983, 44 (C9), pp.C9-563-C9-568. 10.1051/jphyscol:1983983 . jpa-00223433

\section{HAL Id: jpa-00223433 https://hal.science/jpa-00223433}

Submitted on 1 Jan 1983

HAL is a multi-disciplinary open access archive for the deposit and dissemination of scientific research documents, whether they are published or not. The documents may come from teaching and research institutions in France or abroad, or from public or private research centers.
L'archive ouverte pluridisciplinaire HAL, est destinée au dépôt et à la diffusion de documents scientifiques de niveau recherche, publiés ou non, émanant des établissements d'enseignement et de recherche français ou étrangers, des laboratoires publics ou privés. 
ANALYSis AND CRITIQUE OF THE "PEAKIng EFFECT" MODELS : I I

C. Esnouf and G. Fantozzi

Groupe d'Etudes de Métaliurgie Physique et de Physique des Matériaux (LA 341), Institut National des Sciences Appliquées de Lyon, Bât. 502, 20, Avenue A. Einstein, 69621 Vilzeurbanne Cedex, France

Rèsumé - Dans 1'article précédent, nous avons montrê que le modèle de Caro et Mondino ne peut décrire correctement le Peaking Effect. Nous allons maintenant analyser plus prēcisément notre modèle et montrer qu'il permet de donner une bonne description du PE.

Abstract - In the preceding article, we have shown that the Caro and Mondino model cannot give a good description of the Peaking Effect. Now, we analyse more in detail our own model and show that it explains well all the characteristics of the PE.

\section{I - INTRODUCTION}

Our model presented in Manchester (12) is based on the existence of two types of immobile point defects which interact differentiy with dislocations. There are defects localized on dislocations which pin them and defects situated near the glide plane responsible for their retardation. The latter defects provoke an increase $\Delta \tau$ of the relaxation time of the dislocation. This increase depends on $\varepsilon$ because the number of defects met is proportional to the area $\mathcal{A}$ swept out by the dislocation (the deformation $\varepsilon d$ due to the dislocation motion is equal to $\Lambda \mathcal{A b} / L$ where $\Lambda$ is the dislocation density and $L$ the loop length. The $P E$ is due on the one hand to the dislocation pinning which reduces the internal friction and modulus defect and on the other hand to an increase of the dissipated energy due to a dislocation retardation by the second type of points defects. The increase $\Delta \tau$ of the relaxation time is given by (12):

$$
\Delta \tau=C A
$$

where $C$ is proportional to the concentration $\rho$ of points defects created by irradiation $\left(\rho=\rho_{\mathrm{o}} \mathrm{tm}\right)$. $\varepsilon_{\mathrm{d}}$ depends on the strain amplitude $\varepsilon$ by the relation (12):

$$
\varepsilon_{\mathrm{d}}=\varepsilon \Delta / \sqrt{1+\omega^{2} \tau^{2}}
$$

with $\Delta=\Lambda L^{2} G b^{2} / 12 \gamma=$ relaxation strength, $G=$ shear modulus, $\gamma=$ dislocation energy per.unit length $\simeq \mathrm{Gb}^{2} / 2$ ). Thus, we obtain :

$$
\Delta \tau=\frac{C L^{3} G b \varepsilon}{12 \gamma \sqrt{1+\omega^{2} \tau^{2}}} \simeq c_{0} \frac{\rho_{0} L^{3} \varepsilon}{6 b} \frac{t^{m}}{\sqrt{1+\omega^{2} \tau^{2}}}
$$

$\left(C_{0}=\right.$ constant $)$

The dislocation pinning can be describe by the following law:

$$
L=L_{0}(1+a \phi t)^{-n} \text { with a and } n \text { : constants, } \phi \text { : irradiation flux. }
$$

So, $\frac{\Delta}{\Delta_{0}}=\left(\frac{L}{L_{0}}\right)^{2}=\frac{K_{0}}{K}=(1+a \phi t)^{-2 n}$

$\Delta_{0}=$ relaxation strength at $t=0, K=$ Tine tension term $=12 \mathrm{r} / \mathrm{L}^{2}(4)$.

The modulus defect $\triangle M / M$ and the internal friction $Q^{-1}$ are calculated by 
considering that the relaxation time $\tau$ is the sum of three contributions due to the different processes which intervene :

$$
\tau=\tau_{0}+\frac{B_{0}}{K}+\Delta \tau
$$

$\tau_{0}$ is the term associated with a thermally activated phenomenon (Bordoni peak for instance). $B_{0} / K$ is an athermal term where the viscosity coefficient $B_{0}$ is related to phonon effects. These two terms ( $\tau_{0}$ and $B_{0} / K$ ) determine the internal friction before irradiation. The modulus defect and internal friction are given by the classical equations :

$$
\frac{\Delta M}{M}=\frac{\Delta}{1+\omega^{2} \tau^{2}} \quad \text { and } \quad Q^{-1}=\Delta \frac{\omega \tau}{1+\omega^{2} \tau^{2}}
$$

( $\Delta \tau$ is a function of $\varepsilon$ and so the equation of motion of the dislocation is nonlinear ; but we can consider a linear equation with a mean value for $\Delta \tau$ for calculating $Q^{-1}$. Rigorousiy, the equation should be resolved numerically but the conclusions should be similar).

\section{II - MODEL ANALYSIS}

The total relaxation time is given by the following relation (15):

$$
\tau=\tau_{0}+\frac{B_{0}}{k_{0}}(1+a \phi t)^{-2 n}+\frac{k_{0} \varepsilon t^{m}(1+a \phi t)^{-3 n}}{\sqrt{1+\omega^{2} \tau^{2}}}
$$

with

$$
\mathrm{k}_{0}=\frac{}{6 \mathrm{~b}}
$$

An approximate expression for $Q^{-1}$ and $\Delta M / M$ can be obtained when $\omega \tau$ is $\ll 1$, which is true when $\tau_{0}$ is $\approx 0$ (i.e. far from a relaxation peak) and when $B_{0} / K$ is low (low internal friction background).

With this hypothesis, we obtain :

$$
\frac{\Delta M}{M} /\left(\frac{\Delta M}{M}\right)_{0} \simeq \frac{\Delta}{\Delta_{0}} \quad \frac{Q^{-1}}{Q^{-1}} \simeq \frac{\Delta}{\Delta_{0}} \frac{\tau}{B_{0} / K_{0}}
$$

thus

$$
\begin{aligned}
& M=\frac{\Delta M}{M} /\left(\frac{\Delta M}{M}\right)_{0} \simeq(1+a \phi t)^{-2 n} \\
& F=Q^{-1} / Q^{-1} \simeq(1+a \phi t)^{-4 n}\left[1+x t^{m}(1+a \phi t)^{-n}\right]
\end{aligned}
$$

where $x=\frac{k_{0} \varepsilon k_{0}}{B_{0}}=\frac{k_{0} \varepsilon \omega \Delta_{0}}{Q^{-1}}$

The subscript 0 indicates $t=0$.

(However, even when wT is not $\ll 1$, the same conclusions as the following can be obtained).

The principal features of our model are as follows:

i) The PE existence and height depend on the term $x$ : when $x$ is too low there is no PE and only a decrease of $Q^{-1}$. So, we can specify the effect of :

- strain amplitude $\varepsilon$ : the higher the amplitude, the higher is the PE as shown by fig. 5 where the PE is calculated from equation (12). 
- The initial background : $\dot{x}$ is proportional to $Q_{0}$, thus the effect of $\varepsilon$ and $Q_{0}$ are similar. Fig. Ga shows the variation of the PE height with $\varepsilon$ for different values of the initial background and Fig. $6 \mathrm{~b}$ presents the same variation with $Q^{-1}$ for different amplitudes $\varepsilon$, we can note that the variation of the PE height is almost linear as a function of $\varepsilon$ or $Q_{0}$ (except for low values).

- The plastic deformation : the PE depends on the plastic deformation $\varepsilon_{\mathrm{p}}$ on account of the dependence of the term $k_{8}$ with $L_{0}\left(k_{0} \alpha L_{0}^{3}\right)$. If the loop length $L_{0}$ varies as $1 / \varepsilon_{p_{p E}}(4)$, we have $x \propto k_{0} \propto \varepsilon_{p}-3$; so, an initial plastic deformation decreases the PE compared with an undeformed state.

ii) The evolutions of modulus defect and internal friction depend on the existance of the PE. Indeed, let's consider the expressions of $M$ and $F$ given by relations (15) for two cases:

$x=0$ or very low (there is no $P E$ ) : we have $M^{2}=F$; so, the slope of the straight $i$ ine $\log M$ versus $\log F$ is $1 / 2$. (Fig. $7 a$ and $a^{\prime}$ ). mately by :

$\therefore$ higher and for significant $t$ (there is a PE) $F$ and $M$ are given approxi-

$$
F \simeq x t^{m}(a \phi t)^{-5 n} \quad M \simeq(a \phi t)^{-2 n}
$$

Thus, $\quad F$ a $M(5-m / n) / 2$

The slope of the line $\log M=f(\log F)$ is equal to $p=\frac{2}{5-m / n}$ and thus varies from specimen to specimen. In Fig. $7(b, c)$, we have $n=0.3$ and $m=1 / 3$ or $2 / 3$ and $p \simeq 0,51$ or 0,72 respectively.

iii) The position of the $P E$ maximum $\phi t_{M}$ is linked to the value of $x=k_{0} \varepsilon K_{0} / B_{0}$ (fig. 8) : it varies as $\log x$ (excepted for high or very low $x$ values). This slope of the curves is almost independent on the initial background $Q^{-1}$ as predicted by relation (15) but depends strongly on $m$ and $n$ exponents. tive $\mathrm{d} Q-1 / \mathrm{d} \tau$.

4i) The effect of principal parameters on the PE is elucidated by the deriva-

a) The PE height depends on the temperature. In the range $T_{0}<T_{p}, T_{p}:$ temperature of a relaxation peak (due to the term $\tau_{0}$ ), there is no PE (the derivative is negative). In the range $T>T_{p}$, appears but becomes decreasingly as $T$ nears $T$. Indeed, the initial background increases and so the rt decreases as indicated in $i$ ).

b) The PE variation with the strain amplitude (or $Q_{0}$ ) shows a saturation because the derivative $\mathrm{dQ}^{-1} / \mathrm{dT}$ decreases when $\tau($ or $\varepsilon$ ) increases. The maximum value of the PE height is obtained when $\omega \tau=1$.

$5 i$ ) When the term $B_{0}$ is independent of frequency, the PE is also independent on frequency as shown by the $x$ parameter (relation (16)) :

$$
x=k_{0} \frac{\varepsilon k_{0}}{\dot{B}_{0}}=k_{0} \varepsilon \frac{\omega}{Q^{-1}}
$$

This hypothesis requires that the background $Q^{-1}$ is proportional to $\omega, \Delta_{0}$ being constant. This variation has been observed often in the khz and $:$ h $h z$ range but is not observed at low frequency.

\section{III - COMPARISON WITH EXPERIMENTAL RESULTS}

-i) a) The genera 1 form of the curves $Q^{-1}(t) / Q^{-1}$ and their evolution with $\varepsilon$ (fig. 5) are very similar to the experimental results. The coefficients a, $n$ and $m$ must be fitted to obtain the best agreement. a and $n$ are obtained by measuring simultaneously internal friction and modulus defect; indeed, we have : 

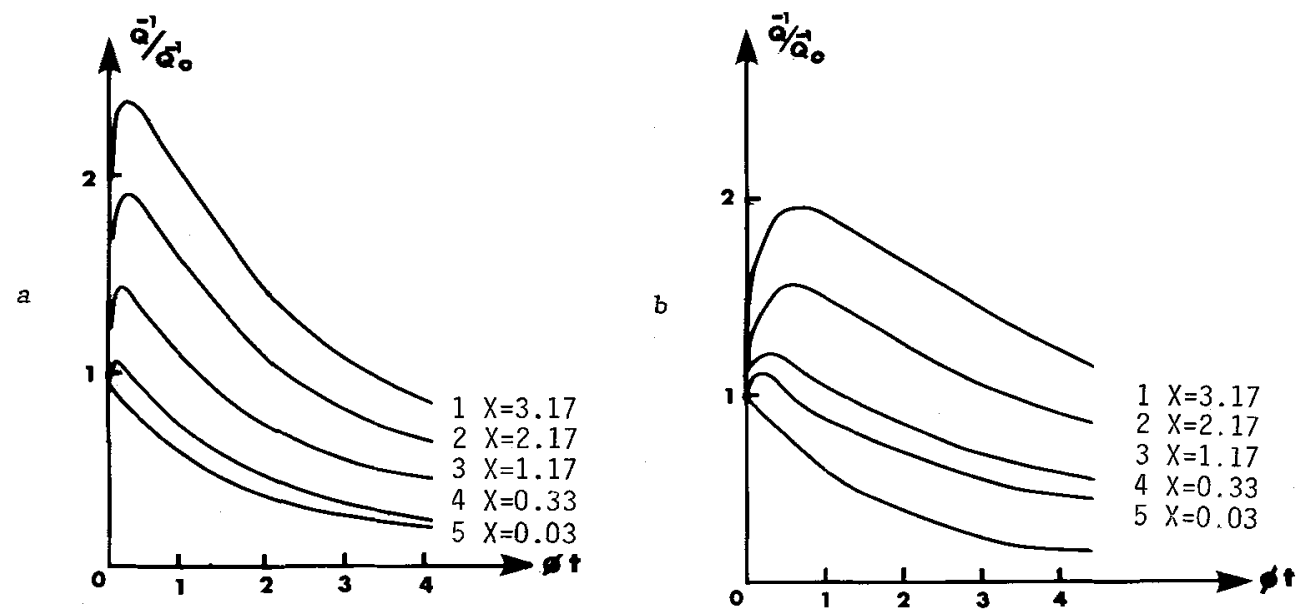

Fig. 5 - PE calculated from equation (15) for different values of $\mathrm{X}$ $\mathrm{a}=0.7 \times 10^{-15} \mathrm{~cm}^{2}, \mathrm{n}=0.3, \mathrm{~m}=1 / 3(\mathrm{a}), \mathrm{m}=2 / 3(\mathrm{~b})$.
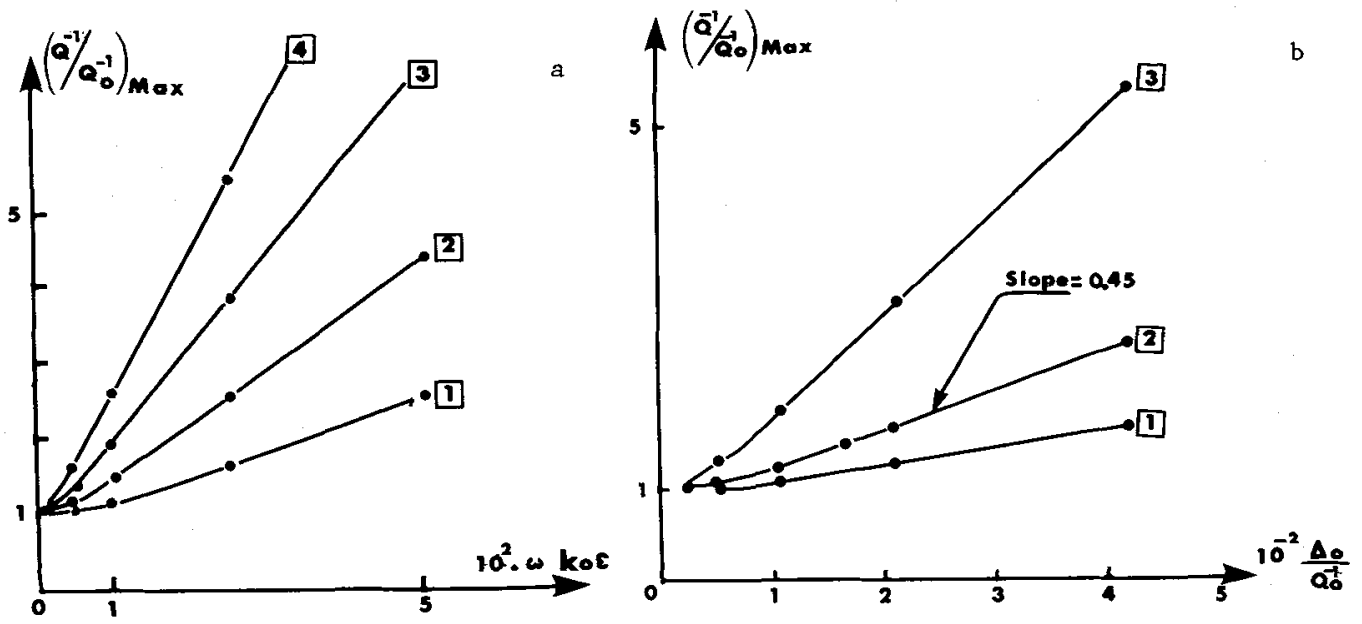

Fig. 6 - Variation of the PE height (a) with $\varepsilon$ : (1) $\mathrm{Q}_{\mathrm{O}}^{-1}=2.10^{-3}$ (2) $10^{-3}$ (3) $6.10^{-4}$ (4) 4.10-4 (4) $4.10^{-4}$; (b) with $Q_{0}^{-1}:$ (1) $x=0.83$ (2) $x=1.67$ (3) $x=4.17$ (a $=0.7 x 10^{-15}$, $\mathrm{m}=1 / 2, \mathrm{n}=0.3)$.

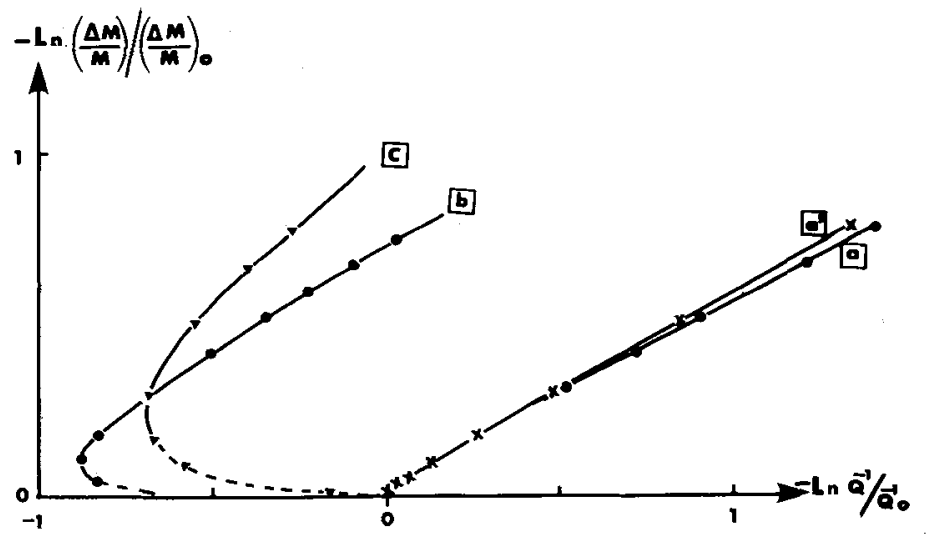

Fig. 7 - Variation of $\log$ $\triangle \mathrm{M} / \mathrm{M}$ as a function of $10 \mathrm{~g}$ $\mathrm{Q}^{-1}: \mathrm{a}=0.7 \times 10^{-15}$ $\mathrm{n}=0.3$, (a) $\mathrm{m}=1 / 3$,

$\mathrm{x}=0.167$ ( $\left.\mathrm{a}^{\prime}\right) \mathrm{m}=2 / 3$

$\mathrm{x}=.0 .167(\mathrm{~b})=\mathrm{m}=1 / 3$

$\mathrm{x}=3.17$ (c) $\mathrm{m}=2 / 3$

$x=3.17$. 


$$
\frac{\Delta M / M}{(\Delta M / M)^{2}+\left(Q^{-1}\right)^{2}}=\frac{K}{\Lambda G b^{2}} \propto L^{2}=L_{0}^{2}(1+a \phi t)^{-n}
$$

The variation of this ratio during irradiation gives a and $\mathrm{n}$ (4). For example, we have $a=0.7 \times 10^{-15} \mathrm{~cm}^{2}, n=0.3$ for $\mathrm{Ag}(3,4)$ and $a=1.41 \times 10^{-15} \mathrm{~cm} 2, n=0.5$ in $\mathrm{Cu}(4)$. The maximum position $\phi t_{y}$ gives $m$ but a more precise value can be obtained by using the variation of $\phi t_{M}$ with $\varepsilon$.

b) The linear dependence of the PE height with $Q_{0}$ observed by Caro (5) is well described by our model (fig. $6 \mathrm{~b}$ ), except for the high values of $Q^{-1}$ (or low $P E)$. The slopes of the 1 ines $Q^{-1}$ max $/ Q^{-1}=f\left(Q_{0}\right)$ are approximately $10^{-3} \Delta_{0}$ $\left(4.5 \times 10^{-3}\right.$ for $\omega k_{0} \varepsilon=10^{-2}$, fig. $\left.6 \mathrm{~b}\right) 1$.e. near $10^{-4}$ with $\Delta_{0} \approx 0.1$. This value is near the value obtained by Caro (5) in the case of $\mathrm{Cu}\left(5 \times 10^{-4}\right)$.

c) The Grenoble Group has shown that the PE decreases when the amount of plastic deformation increases in agreement with our model.

ii) The slope $p$ of the experimental line $\log M$ versus $\log F$ is always one half when there is no PE and $\varepsilon$ is low (4). When the PE appears, this slop is about 1. According to our mode $1, p$ is equal to $1 / 2$ wi thout $P E$ and $p=2 /(5-m / n)$ for long time when the PE is present. This value of $p$ depends on the experimental conditions, microstructural state of the specimen and its temperature (4).

iii) The linear dependence of the PE maximum position $\phi t_{y}$ with $\log \varepsilon$ is well verified by experimental results in $\mathrm{Ag}(3)$ and $\mathrm{Cu}$ (4). From the slope of the curve $\phi t$ versus $\log \varepsilon$ we can obtain a precise value of exponent $m(m=0.45$ in $\mathrm{fog}$ ). One can note that a reduction of loop length by plastic deformation (4) produces a simitar effect to a decrease of $\varepsilon$.

4i) a) Often, the PE has been studied at temperature higher than the temperature $T_{p}$ of Bordoni peaks. When the temperature is near $T_{p}$, the $P E$ becomes low and disappears for $T=T_{p}(4,11)$. This result agrees well with our model. However, some authors nave observed a $\mathrm{PE}$ pelow the Bordoni peak $(4 \mathrm{~K})$, which can be due to the secon kind of Peieris valleys (11).

b) The experimentally observed saturation of the PE height with the strain amplitude $\varepsilon$ (fig. 3 ) is due to the fact that the internal friction cannot exceed the relaxation strength. Thus the PE dependence on $\varepsilon$ varies with temperature : the saturation is observed earlier when the temperature is nearer the Burdoni peak as seen on Fig. 3.

5i) The PE independence of the applied frequency shows that the ratio $\mathrm{K}_{0} / \mathrm{B}_{0}$ must stay constant (relation (16)). But, the initial background $Q^{-1} \simeq Q_{0} \omega B_{0} / K_{0}$ must vary linearly with $\omega$. Caro (5) has observed an inverted variation. Sut it would be necessary to study the ratio $Q^{-1} / \Delta_{0}$. Indeed, the relaxation strength decreases when the applied frequency increases, as observed by several authors $(1)$. Therefore, it would be desirable to measure $Q^{-1} 0$ and $\Delta_{0}$ versus frequency to specify the frequency effect.

IV - CONCLUSION

The comparison of experimental results with the preceding theoretical analysis shows that our model describes the principal features of the PE. Our model can be improved by taking into account some secondary effects such as the depinning of loop lengths with $E$, responsible for the variation of $Q^{-1}{ }_{0}$ with $\varepsilon$. Thus, a better agreement with experimental results can be obtained. Eut, such an effect is not necessary to obtain a PE as in the Caro and Mondino model. A better aqreement with experiments can be also obtained by choosing a better law for the variation of ]oop lengths : the law $L=L_{0}(1+a \phi t)^{-n}$ can be replaced by the 1 aw $1 /\left[1+a(\phi t)^{-n}\right]^{\text {as }}$ proposed by Lauzier (4). 
Lastly, we have shown that the existence and the non-linear effects of the PE are not linked to the initial background dependence on the strain amplitude this dependence is only responsible for some secondary effects only.

\section{REFERENCES}

(1) SIMPSOH H.H., SOSIN A, and JOHNSON D.F., Phys. Rev. P, 5, 4, (1972) 1393

(2) SEIFFERT S.L., SI:APSON H.1. and SOSIi: A, J. App1. Phys. 44, 8, (1973) 3404

(3) GIRARS P. and MINIER C., J. Phys. 39, (1978) 981

(4) LAUZIER J., Thèse, Université de Grenoble, 1981

(5) CARO J., Thèse, E.P.F. Lausanne, 1981

(6) CARO J., MONDiNO M. , J. Appl. Phys. 52, (1981) 7147

(7) LAUZIER J., MINIER C. and SEIFFERT S.L., Phil. Mag. 31, (1975) 893

(8) SIMPSON H.M., SOSIN A. and SEIFFERT S.L., J. App1. Phys. 42, (1971) 3977

(9) BOnJour C., Thèse, E.P.F. Lausanne, 1978

(10) MINIER C., LAUZIER J., ESHOUF C. FANTOZZI G., Phys. Stat. Sol. (á)71 (1982)381

(11) MINIER C., LAUZIER J., ESNOUF C., FANTOZZI G., this conference

(12) ESNOUF C. and FANTOZZI G., 3 ECIFUAS, Manchester, ed. C.C. SMITH, Pergamon Press, (1980) p. 109

(13) CARO J., GLASS N.E. and MONDINO M., J. App1. Phys. 53, 7, (1982) 4854

(14) GRANRTO A.V. and LUCKE K., J. A.pp1. Phys. 27, (1956) 583

(15) RITCHIE I.G., R.TRENS A., SO C.R. and SPRUIGAMAM! K.W., J. Phys. C5, 10,42(1981)310

(16) FANTOZZI G., ESHOUF C., BENOIT W., RITCHIE I., Prog. Mat. Sci. 27, 3-4(1982) 311

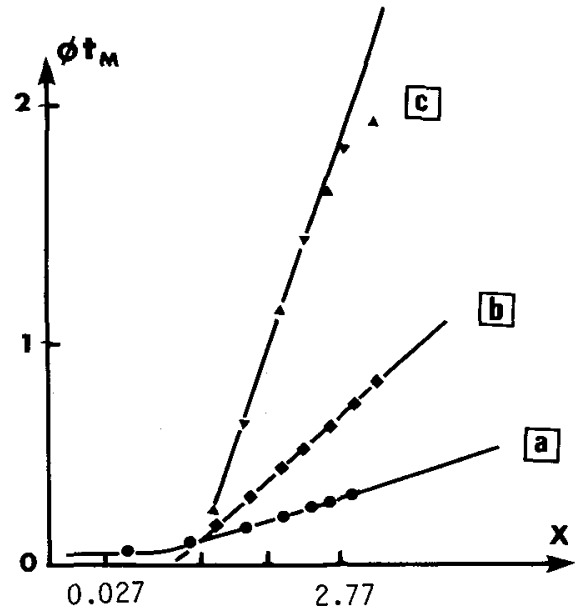

Fig. 8 - Variation of the integrated flux $\emptyset t_{M}$ at the PE maximum with $\mathrm{X}$ : (a) $\mathrm{m}=1 / 3$ (b) $\mathrm{m}=2 / 3$ (c) $\mathrm{m}=1$ $\left(\mathrm{a}=0.7 \times 10^{-15}, \mathrm{n}=0.3, \mathrm{Q}_{0}^{-1}=10^{-3}\right.$ $\Lambda \mathrm{L}_{\mathrm{O}}^{2}$ ).

Acknowledgments : the authors are grateful to Dr. I. RITCHIE for transfation. 